\title{
El trasfondo de la Ley de Seguridad Interior en México
}

The background of the internal security law in Mexico

Autores: José Fernando Vázquez Avedillo, Raúl Ruiz Canizales, Rafael Zúñiga Domínguez

DOI: https://doi.org/10.25058/1794600X.1001

\footnotetext{
SP MISIÓN JURÍDICA A 


\section{EL TRASFONDO DE LA LEY DE SEGURIDAD INTERIOR EN MÉXICO*}

\author{
THE BACKGROUND OF THE INTERNAL \\ SECURITY LAW IN MEXICO
}

O PLANO DE FUNDO DA LEI DE SEGURANÇA INTERNA NO MÉXICO
José Fernando Vázquez Avedillo ${ }^{\mathrm{a}}$ fvaasesoria@gmail.com Raúl Ruiz Canizales raul.canizales@hotmail.com Rafael Zúñiga Domínguez ${ }^{c}$ r181093z@icloud.com

Fecha de recepción: julio 04 de 2018 Fecha de revisión: febrero 27 de 2019 Fecha de aceptación: marzo 07 de 2019

\section{RESUMEN}

La idea de gobierno al seno de un país implica necesariamente el ejercicio del poder y para ello es menester contar con ciertos elementos para lograrlo. Históricamente el uso de las fuerzas armadas ha sido el sostén de muchos gobernantes en todo el mundo y en el caso de México no es la excepción. La publicación de la Ley de Seguridad Interior fue realizada con la intención de empoderar al presidente de la República y a partir de ahí mantener la gobernabilidad a partir del uso de las fuerzas armadas en funciones de seguridad pública bajo el disfraz de la seguridad nacional, circunstancia que implicaría flagrantes violaciones a los derechos humanos de la población.

Podemos señalar que los resultados que arrojó la investigación fueron el haber encontrado un patrón de conducta en los

*Artículo de reflexión.

a. Doctor en Derecho, Profesor de tiempo completo adscrito a la facultad de Derecho de la Universidad Autónoma de Querétaro. Miembro del Cuerpo Académico "Derechos Humanos y Globalización".

b. Doctor en Derecho, Profesor de tiempo completo adscrito a la facultad de Derecho de la Universidad Autónoma de Querétaro. Miembro del Cuerpo Académico "Derechos Humanos y Globalización".

c. Pasante de la licenciatura en Derecho en la Universidad Autónoma de Querétaro. Exp. 233685. 
gobernantes, consistente en el uso y abuso de las fuerzas armadas para el mantenimiento de la gobernabilidad democrática del país; la ley contenía en su articulado sendas expresiones que dotaban de poderes extraordinarios al titular del Poder Ejecutivo, a efecto de llevar a cabo labores de seguridad pública mediante el uso de las fuerzas armadas, y que con la ley criticada, se pretendía legitimar el uso de las fuerzas armadas para asuntos de naturaleza civil, circunstancia que fue considerada por la Suprema Corte de Justicia de la Nación para efecto de declarar a la ley en comento como inconstitucional.

\section{PALABRAS CLAVE}

Gobierno; poder; fuerzas armadas; ley.

\section{RESUMO}

A ideia de governo dentro de um país implica necessariamente o exercício do poder e para isso é necessário ter certos elementos para alcançálo. Historicamente, o uso das forças armadas tem sido o apoio de muitos governos em todo o mundo e, no caso do México, não é a exceção. A publicação da Lei de Segurança Interna foi feita com a intenção de capacitar o Presidente da República e de lá manter a governabilidade do uso das forças armadas em funções de segurança pública sob o disfarce de segurança nacional, uma circunstância que envolveria violações flagrantes dos direitos humanos da população.

Podemos apontar que os resultados da investigação foram a constatação de um padrão de comportamento nos governantes, consistindo no uso e abuso das forças armadas para a manutenção da governança democrática no país; A lei continha em seus artigos cada expressão dando poderes extraordinários ao chefe do Poder Executivo, a fim de realizar o trabalho de segurança pública através do uso das forças armadas, e que, com a lei criticada, pretendia legitimar o uso de as Forças Armadas para assuntos de natureza civil, circunstância que foi considerada pelo Supremo Tribunal de Justiça da Nação com a finalidade de declarar a Lei inconstitucional.

\section{PALAVRAS-CHAVE}

Governo; poder; forças armadas; lei.

\section{ABSTRACT}

The idea of a government in the heart of a country necessarily implies the exercise of power and to obtain it is necessary to have certain elements. Historically the use of the armed forces has been the mainstay of many rulers worldwide and Mexico has not been an exception. The publication of the Internal Security Law has been done with the intention of empowering the president of the republic and from there to mantain governability through the use of the armed forces in public security functions under the disguise of national security, a circumstance that would imply a gross violation of the human rights of the population.

We can point out that the result that the investigation has shown a pattern of behavior of governors consisting of the use and abuse of armed forces to mantain the democratic governability of the country, the law held in its articles expressions that gave extraordinary powers to the head of the Executive Power, for the purpose of carrying out public security tasks by the use of armed forces for civil issues, condition that has been considered by the National Supreme Court of Justice to declare this law as unconstitutional.

\section{KEYWORDS}

Government; power; armed forces; law.

\section{Introducción}

Siempre se ha pensado que las reglas tienen que ver con la regulación de situaciones al seno de una sociedad o para dar estructura, organización $\mathrm{y}$ funcionalidad a un órgano de gobierno, sin embargo, la teleología de un dispositivo legal constantemente conlleva otras finalidades, que no siempre son visibles a todos, y que por lo tanto, solo son comprendidas por algunos cuantos dedicados a ciertos temas como lo puede ser el ámbito meramente legal, pero también aquellos relacionados con ciencia política, sociología, etc.

En virtud de lo anterior, la pretensión de este trabajo va dirigida a demostrar que la Ley de Seguridad Interior, más allá de justificar la intervención de las fuerzas armadas en asuntos de seguridad, estaba encaminada a empoderar al titular del Poder Ejecutivo en México, el cual, desde hace algunos años ha 
venido experimentando la pérdida formal $y$ sobre todo material de poder, dando pauta al repunte del legislativo, del judicial e incluso de los gobernadores de las entidades federativas.

A efecto de lograr la empresa señalada y con el herramental del método inductivo, desde un enfoque cualitativo y utilizando técnica de investigación documental, se hará una breve puntualización de cómo ciertos gobernantes a lo largo del tiempo, han logrado su cometido cuando han contado con el apoyo de las fuerzas armadas, circunstancia que nos dará la posibilidad de analizar para el caso mexicano, el cómo ha sido la distribución del poder en México, particularmente en lo referente al uso del ejército como el principal punto de apoyo para alcanzar pleno poder; hecho esto, daremos paso a un análisis de los aspectos torales de la Ley de Seguridad Interior, de los cuales se advertirá esa pretensión de empoderamiento del titular del Poder Ejecutivo, culminando con algunas reflexiones que consideramos pertinente tener en cuenta a efecto de demostrar la idea primigeniamente planteada.

\section{LA BALANZA DEL PODER EN MÉXICO}

Comenzaremos por hacer una precisión que resulta por demás necesaria en este punto del trayecto y se refiere a la temporalidad que implica un análisis del tópico del poder en un país como el nuestro. En este sentido, para poder demostrar claramente el sentido que pretendemos dar a este trabajo de investigación, nos referiremos al fenómeno de la distribución del poder, digamos, de los albores del siglo XX a nuestros días, algo así como un estudio de alrededor de 100 años de historia, particularmente referida hacia el sistema de gobierno ${ }^{1}$ que hemos tenido en este tiempo, sin que esto sea óbice para hacer alguna referencia hacia fenómenos semejantes ocurridos en otras latitudes y en otros tiempos.

Para poner un punto de partida, haremos referencia a lo que debemos entender por Estado, desde el punto de vista de Jellinek quien señala lo siguiente: “(...) el Estado es la unidad de asociación dotado originariamente de poder de dominación, y formada por hombres asentados en un territorio" (2004: 171).

1. No confundir la forma de estado, la forma de gobierno y el sistema de gobierno.
Lo que Jellinek nos quiso señalar es que el Estado es una corporación formada por un pueblo, dotada de un poder de mando originario y asentada en un determinado territorio. Derivado de esta definición, sale a colación el asunto del poder, el cual termina siendo ejercido por un gobierno en representación del pueblo; ese gobierno puede tener una composición diversa, dependiendo del lugar y la época de la que hablemos.

Para comprender lo anterior, recurriremos inicialmente a Nicolás Maquiavelo, quien desempeñándose como consejero de príncipes o de reyes, estableció que la preservación del poder político siempre estaría por encima de cualquier consideración de orden ético; además, señalaba que la fuerza es el origen del poder y pasa por encima de las razones y de los pactos entre pares. (Maquiavelo, 1993).

Esta idea de Maquiavelo sobre el ejercicio del poder y el uso de la fuerza dentro de los que en su época se denominó como el Estado, no fue desconocida para pueblos de la antigüedad; para poner un ejemplo contundente nos referiremos al Imperio Romano, donde el emperador en turno sostenía buena parte de su posición gracias al apoyo que le brindaba el ejército y particularmente la guardia pretoriana, la cual fue concebida por Augusto durante su mandato.

La guardia pretoriana fue fundada por Augusto en 27 o 26 a.C. En principio se crearon nueve cohortes, aunque su número fluctuó hasta que a finales del siglo I d.C. se estableció en diez. Cada cohorte contaba con unos 480 hombres más un complemento de alrededor de cien jinetes llamados equites pretoriani. Se cree que en la primera mitad del siglo II d.C. se aumentó a mil el número de efectivos por cohorte. Al mando de la guardia pretoriana había normalmente dos prefectos del pretorio, que debían ser militares experimentados pertenecientes al orden de los caballeros, la clase adinerada que ocupaba importantes cargos en la administración y el ejército.

Entrar en la guardia pretoriana era sumamente apetecible, no solo por el honor que suponía custodiar al emperador, sino también por las ventajas económicas que el puesto traía aparejadas. El sueldo de los pretorianos era el más elevado de todas las unidades del ejército romano. A finales del gobierno de Augusto, la cantidad base anual ascendía a 
3.000 sestercios, mientras que un legionario cobraba 900. Hay que considerar también los donativos extraordinarios que les otorgaban los emperadores en acontecimientos como el ascenso al poder, campañas victoriosas o celebraciones especiales, y que eran siempre mayores que las que pudieran ofrecerse a las tropas legionarias. En su testamento, Augusto ordenó que se entregaran 1.000 sestercios a cada pretoriano, por solo 300 a los legionarios, y muchos de sus sucesores les hicieron generosos donativos nada más acceder al poder para asegurarse su fidelidad: Claudio les concedió 15.000 sestercios, y Marco Aurelio y Lucio Vero, ya en el siglo II d.C., 20.000. (National Geographic, 2018)

Al igual que los romanos, muchos otros pueblos alrededor del mundo han basado la supervivencia de su gobierno con base en el uso de la fuerza, particularmente de la fuerza militar.

Esta idea del ejercicio del poder sustentada por Maquiavelo, fue retomada por Hobbes en su obra Leviatán, donde señaló: "que el hombre se encuentra en un estado permanente de guerra, y donde los individuos se enfrentan los unos a los otros en busca de beneficios específicos mediante el uso de la fuerza" (Hobbes, 2006: 104-107).

Por otra parte, Max Weber, cuando define al Estado, hace referencia a la reivindicación que este realiza del monopolio del uso legítimo de la fuerza dentro de un territorio, circunstancia por la que puntualiza que el Estado es la fuente de la legitimidad del uso de la violencia, siendo la policía y los militares sus principales instrumentos de acción. (Weber, 2002: 662)

Aunque podríamos seguir citando a diversos autores que nos hablan del uso de la fuerza como herramienta para el ejercicio del poder, lo importante es dejar asentado el hecho de que el uso del ejército en diversos lugares y épocas ha sido decisivo para obtener y conservar el poder.

Ahora bien, y siguiendo por la línea del ejercicio del poder, para nuestro caso, es decir, el mexicano, podemos hacer referencia a la tipología clásica de la división del poder, misma que nos refiere a la existencia de tres, a saber: el Legislativo, el Ejecutivo y el Judicial. Habrá que señalar que esta tipología clásica de la división del poder ha sido superada con la aparición de funciones emergentes como las desarrolladas por los órganos constitucionales autónomos.

Dejando un momento de lado la tipología del poder, daremos cuenta particularmente del sistema de gobierno que hemos tenido desde hace cien años aproximadamente y de manera casi ininterrumpida, es decir, el sistema presidencial.

Cuando hablamos del sistema de gobierno, nos referimos al fenómeno de la distribución del poder, es decir, el poder en manos de una persona o en manos de una asamblea, derivándose de esto dos posibilidades: el sistema parlamentario y el sistema presidencial.

Hablar de un sistema parlamentario implica que el ejercicio del poder recae en una asamblea de naturaleza legislativa tal como es un parlamento, el cual domina el escenario e impone condiciones a quien encarna la función ejecutiva que en el caso suele ser un primer ministro, el cual junto con toda la cartera de ministros son elegidos por ese órgano colegiado y por lo tanto se encuentran supeditados al mismo. En este caso es claro señalar que el pueblo elige a los miembros del parlamento, pero no a la rama ejecutiva del poder. Un caso que ejemplifica claramente el modelo parlamentario es justamente el caso de Inglaterra, donde el Parlamento se encuentra integrado por la Cámara de los Comunes, la Cámara de los Lores y desde luego, la Reina. Esta asamblea se encarga de elegir al Primer Ministro y al resto de los miembros de la rama ejecutiva, quienes como ya se dijo están subordinados al Parlamento.

En el caso del sistema presidencial, quien domina el escenario es justamente el titular de la función ejecutiva, la cual tiene como característica $\mathrm{su}$ independencia de la función legislativa, quedando por ello de manera independiente, puesto que su nombramiento generalmente proviene de un proceso electoral donde es el pueblo quien lo elige de manera directa y periódica, y además, por un espacio determinado de tiempo, de manera que es prácticamente imposible su separación por determinación del legislativo.

Lapalombara, (2006) afirma que en un sistema presidencial, el presidente, quien es jefe de estado y de gobierno a la vez, es independiente del poder legislativo y por tanto no depende mayor ni continuamente de este para su existencia y sobrevivencia; los poderes legislativo 
y ejecutivo son interdependientes: el legislativo no está obligado a aprobar los proyectos de ley que provienen del ejecutivo, el presidente puede vetar las leyes del legislativo; el presidente tiene la facultad de realizar nombramientos, el legislativo tiene la facultad de autorizar o no recursos económicos; el ejecutivo puede apelar directamente al pueblo a través de plebiscitos y referendos, el legislativo puede juzgar y remover al presidente (Carpizo, 2006: 12,13).

Dicho lo anterior, el caso mexicano corresponde a un sistema de gobierno presidencial, cuyo sustento se encuentra en los artículos 41,49 y 80 constitucionales, donde se deja de manifiesto la separación de las funciones del poder y la preponderancia del ejecutivo respecto del legislativo y judicial -al menos desde el punto de vista formal-.

Habiendo dejado anotados los elementos básicos para ubicar lo que debemos entender por sistema de gobierno y desde luego ubicando el mexicano como un régimen presidencial, ahora, toca en turno hacer un brevísimo recorrido histórico para tratar de comprender el porqué de nuestro actual sistema de gobierno, como resultado de una serie de acontecimientos sociales, culturales y desde luego políticos.

Remontémonos hacia el inicio de la etapa posrevolucionaria ${ }^{2}$, donde existen una serie de liderazgos que luchan encarnizadamente por llegar a la presidencia de la república, apareciendo en el mapa político un personaje que vino a poner orden mediante el uso de la fuerza y desde luego con el apoyo del ejército, y nos referimos al general Álvaro Obregón, quien, tras las elecciones de septiembre de 1920, tomaría la presidencia de la república hasta el año de 1924.

Una de las características medulares de aquel régimen presidencial era justamente la hegemonía que tenía el presidente, el cual era gracias no solo a su carisma y liderazgo político y social, sino también al apoyo del ejército y de su grupo político, el cual también se encargó de colocar a determinados personajes en puestos clave de la función legislativa, circunstancia con la que Álvaro Obregón, al ser el líder del movimiento y presidente de la república dominaba sin problema alguno todo el escenario político del país.

2. Hacia el año de 1920 .
Bajo esa tesitura, siguieron otros muchos presidentes que se erigieron como el hombre fuerte del país, capaces de transformar la realidad mexicana con solo un elemento: su voluntad, ya que el resto de las funciones del poder se encontraban supeditadas a ese gran tlatoani ${ }^{3}$. En este sentido resulta a todas luces pertinente referirnos al General Plutarco Elías Calles y por supuesto al General Lázaro Cárdenas, quienes con el apoyo militar también lograron consolidar sus gobiernos. El caso del General Elías Calles es muy interesante pues mantuvo el control del gobierno durante su cuatrienio y seis años posteriores desde bambalinas, periodo conocido como el Maximato, mismo que culminó con el arribo del General Lázaro Cárdenas a la presidencia de la república, circunstancia que sucedió, entre otras cosas, por el apoyo militar con el que contaba. Maximato lo describe Medin (2003).

El periodo que se extiende desde 1928 hasta 1934-5 es conocido como el Maximato, es el periodo en el que Plutarco Elías Calles fue reconocido como el Jefe Máximo de la Revolución y durante el cual era el factor decisivo de las decisiones políticas (Medin, 2003: 23).

Desde luego no debemos olvidar el hecho de la conformación partidista en aquel momento de la historia de México, que naturalmente incluía en un inicio al sector militar. De lo anterior se desprende la aparición en 1928 del Partido Nacional Revolucionario (PNR), el cual se transformaría en el año de 1938 en Partido de la Revolución Mexicana (PRM), para modificarse en 1946 en el actual Partido Revolucionario Institucional (PRI).

Ahora bien, desde el 10. de diciembre de 1940 el presidente Manuel Ávila Camacho hizo que desapareciera del PRM el "Sector Militar", circunstancia que dio pauta a que, para las elecciones de 1946, llegara el primer presidente de la república de origen civil y nos referimos a Miguel Alemán, el cual siguió contando con el apoyo de las fuerzas armadas pero sin el peligro de que estas tuvieran un acceso directo a la presidencia de la república, como sucedió con sus antecesores.

Básicamente podemos señalar que casi todo el siglo XX transcurrió bajo esa característica en la distribución del poder, donde el presidente

3. Palabra náhuatl para designar a un gobernante. 
era amo y señor del país, sobre todo manejando de facto muchas atribuciones que no estaban expresamente señaladas ni en la Constitución ni en las leyes, circunstancia que fue conocida como el ejercicio de las facultades metaconstitucionales. Serrano, (2006) comenta:

Una vez terminado el periodo armado de la Revolución mexicana, la sociedad y la política en este país emprendieron un proceso de estabilización y crecimiento que se extendió durante más de setenta años. Diversas circunstancias incidieron para que, a lo largo de los años, el presidente de la República ocupara espacios de poder cada vez más grandes y efectivos. Relacionado con esta concentración de poder, las diversas fuerzas públicas, los poderes y las agrupaciones de base y de Estado, coincidieron en afianzar el poder presidencial en torno al cual orbitaban. Todo esto incluyó la formación de facultades que si bien no se encontraban en la Constitución, eran respaldadas o avaladas por todos los actores políticos y ejercidas por el titular del Ejecutivo, al grado de que existía una idea generalizada y compartida tanto del derecho del Ejecutivo para ejercerlas, como del deber de respeto que los actores políticos debían a dichas atribuciones; en resumen, el sentimiento generalizado de legitimidad de las mismas. Esto es, se formó un grupo de facultades metaconstitucionales con efectividad real. (Serrano, 2006: 1)

Es hasta el sexenio de Ernesto Zedillo donde se empieza a observar un cambio en la distribución del ejercicio del poder, particularmente entre 1997 y 2000, donde en la composición de la 57ạ Cámara de Diputados federal, el partido del presidente, es decir, el Partido Revolucionario Institucional pierde la mayoría, alcanzando solamente 239 curules, mientras que la oposición, particularmente el Partido Acción Nacional y el de la Revolución Democrática alcanzaban 121 y 125 respectivamente. (Senado 2006).

Es justamente esta circunstancia la que nos da pauta para hablar del sexenio del presidente Zedillo, donde comienza un proceso de transición en el ejercicio del poder en México.

El presidente Zedillo tomó el poder el $1^{\text {o }}$ de diciembre de 1994 y su sexenio se caracterizó en su primera fase por estar en crisis debido a la insurrección armada en el sureste del país encabezada por el Ejército Zapatista de Liberación Nacional, así como el conflicto económico de magnitud global en el que nos encontrábamos y que fue conocido como el efecto tequila, circunstancias que generó un caos financiero. A pesar de este escenario tan difícil, el régimen logró reunir a las fuerzas políticas del país a efecto trabajar conjuntamente en la búsqueda de soluciones a los problemas existentes y justamente Zedillo logró hacer un pacto denominado Compromisos para el Acuerdo Político Nacional, el cual fue suscrito el 17 de enero de 1995 por el Partido Revolucionario Institucional (PRI), el Partido de Acción Nacional (PAN), el Partido de la Revolución Democrática (PRD) y el Partido del Trabajo (PT), todos con representación en el Congreso de la Unión. Krauze, (2007) expone:

Fue un acto esperanzador. La crisis de México no tenía precedentes desde tiempos de la Revolución, era una crisis integral: económica, social, política. Había inseguridad y violencia en las calles, desánimo y desconfianza en las conciencias. No existían soluciones mágicas o providenciales para lograr la recuperación de los niveles de vida. Quedaba un largo y doloroso trecho por recorrer, pero la condición especial para abordarlo era la reforma democrática. Así lo expresaba Zedillo en privado y en público. En cierto momento habló de la necesidad de crear y mantener una sana distancia entre el presidente y el PRI. Parecía convencido de que la solución de fondo a los problemas de México radicaba en reconocer la quiebra de la vieja empresa, acabar con la simulación, cerrar el teatro (Krauze, 2007: 496).

Dada la conformación política de nuestro país durante el sexenio de Zedillo, a este ya no le fue posible actuar como lo habían hecho sus antecesores, es decir, con absoluta libertad, pues en el caso de aquéllos tenían el famoso carro completo $^{4}$, pero en el caso de Zedillo esto ya no sucedió, como se había relatado líneas arriba. Esta circunstancia lo limitó en su margen de actuación sometiéndolo en todo momento al marco legal y dejando de hacer muchas cosas que habían sido conocidas hasta ese momento -como ya se había mencionado- como las facultades

4. Se dice que se tiene carro completo cuando el presidente de la República cuenta con el apoyo total del Poder Legislativo, por ser la mayoría miembros del mismo instituto político del presidente. 
metaconstitucionales del presidente; esta circunstancia también abonó al hecho de que el presidente Zedillo se convirtiera en artífice de una transición democrática en el año 2000 Cárdenas, (1994), cuando Vicente Fox ganó las elecciones presidenciales, siendo abanderado por el Partido Acción Nacional. Para Serrano (2006)

El control del presidente(sic) de la república sobre los otros poderes federales y sobre los gobiernos locales (que no dudaron en reproducir este modelo autoritario en su ámbito) modificó en los hechos el sistema presidencial previsto en la Constitución y degeneró en un modelo de presidencialismo autoritario de tal envergadura que no dudaron en llamar "dictadura perfecta" o "presidencia imperial". La clave para entender la gestación y la evolución de las facultades metaconstitucionales está en comprender la dinámica que el sistema político mexicano mantuvo por más de siete décadas. (Serrano, 2006: 4).

Desde luego, la llegada de un presidente abanderado por el hasta entonces partido de oposición (PAN), no fue suficiente para lograr una mejoría en las condiciones de vida del pueblo mexicano. El presidente Fox llegó a la presidencia de la república queriendo utilizar las viejas reglas del juego del sistema político mexicano donde la fórmula exitosa requería contar con la mayoría en el Congreso de la Unión, sin embargo, esto no sucedió así ya que en ese momento al seno de la $58^{a}$ Legislatura Federal, el PRI mantuvo 208 diputados y 58 senadores, el PRD 53 diputados y 15 senadores y el PAN solamente 207 diputados y 47 senadores, circunstancia que nos hablaba de un escenario dividido, lo cual provocó un encontronazo entre la rama ejecutiva y la legislativa, sin que se llegaran a grandes acuerdos que posibilitaran un sexenio tranquilo y con buena marcha.

Durante la primera mitad del sexenio de Felipe Calderón Hinojosa (2006-2012), la Cámara de Diputados de la $60^{\underline{a}}$ Legislatura federal tuvo una composición donde el Partido Acción Nacional ocupó 206 curules, mientras que el Revolucionario Institucional solamente tenía 104 y el de la Revolución Democrática 126, circunstancia que ponía de manifiesto que el partido "oficial" ahora el PAN, nuevamente carecía de la mayoría para hacer su voluntad, hecho que se vio de manifiesto con los constantes desacuerdos entre ejecutivo y legislativo.
En el año 2012, el PRI recuperó la presidencia de la república, y la $62^{\text {a }}$ legislatura federal mostró cierto empoderamiento del Partido Revolucionario Institucional, el cual obtuvo 212 curules y 52 escaños senatoriales, mientras que el PAN se redujo a 114 curules y 38 escaños y el PRD 104 curules y 22 escaños. Para la $63^{a}$ legislatura federal, el PRI obtuvo 205 curules y 56 escaños, el PAN obtuvo 109 curules y 37 escaños y el PRD se adjudicó 54 curules y 9 escaños. En este sentido, habrá que recordar que con la aparición del Movimiento de Regeneración Nacional (Morena), la fuerza del PRD mermó significativamente.

Como puede observarse de las cifras vertidas en los párrafos anteriores, desde el año 2000, la presidencia de la república ya no contaba con el apoyo absoluto del Congreso de la Unión, debido a que su partido postulante no representaba esa mayoría absoluta, circunstancia que nos habla claramente de una pérdida de poder de la rama ejecutiva, lo que pudiese haber dado pauta desde aquella presidencia de Fox, a la aparición de coaliciones de gobierno, sin embargo, lo único que se ha observado en estos últimos años ha sido la negativa a colaborar con otras fuerzas políticas, compartiendo el poder, hecho que podría darse a través de las coaliciones, proveyendo al país de un esquema de gobernabilidad democrática mucho más amplio y estable. Valadéz (2016) afirma.

(...) una gobernabilidad democrática entendida como un proceso de decisiones tomadas de manera legal, razonable, responsable y eficaz, adoptadas por autoridades legítimas, que garantizan a la población el ejercicio de sus derechos civiles, políticos, económicos, culturales y sociales, en un ámbito de libertades y de estabilidad, y que atiende los requerimiento de la sociedad mediante políticas que promueven justicia y equidad, prestaciones para el bienestar, y servicios regulares, suficientes y oportunos. (Valadés, 2016: 14).

El resultado de todos estos procesos fue palpable pues la figura presidencial a partir de Fox, ha sido hasta objeto de burla y escarnio público, pues ya no representa al poder. Quién no recordará amargamente cuando un joven le pone cuernos a Vicente Fox en una foto oficial, o las críticas tan duras contra Calderón debido a su guerra contra el narco o su supuesto alcoholismo y desde luego las múltiples críticas a Enrique 
Peña Nieto e incluso al actual presidente López Obrador, quien a pesar de recién haber iniciado su mandato constitucional, tampoco se salva del ataque de muchos sectores del país.

Pero más allá de la crítica a la persona que encarna la función ejecutiva, el problema radica en que el poder presidencial se ha visto mermado significativamente, circunstancia que ha venido a afectar al propio sistema político mexicano basado en la figura del hombre fuerte que todo lo puede y todo lo resuelve.

Hoy en día, la figura del hombre fuerte ya no existe y hasta pudiéramos decir que la función legislativa y la judicial han cobrado mayor fuerza que el propio presidente, y aún más, pues hoy vemos a un grupo organizado de gobernadores que también se disputan parte del pastel político en el país.

La Conferencia Nacional de Gobernadores (CONAGO) es un foro permanente, el cual busca fortalecer el federalismo mediante mecanismos democráticos, manteniendo pleno respeto de las instituciones de México. Éste, es un espacio incluyente, abierto a todas las entidades del país, sin distinción de partidos políticos. (enero de 2013) La Conferencia Nacional de Gobernadores.

De esto último podemos reiterar que el poder no desaparece, sino que solamente cambia de manos y cuando el ejecutivo dejó de utilizar aquellas facultades metaconstitucionales, ese poder fue redistribuido entre los demás entes de gobierno y lamentablemente en algunos ajenos a este, los cuales no necesariamente representan los intereses del pueblo mexicano.

Pero ¿qué es lo que está sucediendo hoy en día en materia de ejercicio del poder?, pareciera que la figura presidencial estuviera de regreso por sus fueros, intentando hacerse del mayor cúmulo de los hilos del poder a efecto de recuperar ese lugar privilegiado que por tanto tiempo se tuvo en nuestro país. En este sentido hay que señalar que parte de ese poder político del que gozaba la presidencia de la república se basaba en la lealtad que le propinaba las fuerzas armadas, siendo esta circunstancia un elemento toral para poder mandar y ser obedecido, so pena de hacer uso de la fuerza que esta noble institución posee.
Una constante en los presidentes mexicanos ha sido el hecho de que una de sus primeras reuniones de gobierno ha sido con las fuerzas armadas, tanto con la Secretaría de la Defensa Nacional (SEDENA) como con la Secretaría de Marina (SEMAR), a efecto de consolidar su vínculo con la Presidencia de la república, hecho que se ha venido dando de manera reiterada al inicio de un nuevo sexenio desde mediados del siglo pasado, sin que el sexenio que recién inicia haya sido la excepción.

A efecto de mostrar alguna evidencia de esta afirmación, es decir, que la fuerza del titular del Poder Ejecutivo radica en gran medida en el vínculo que mantiene con las fuerzas armadas, justamente se procederá al análisis de la Ley de Seguridad Interior 5 , que a juicio de los que suscribimos, abona en su contenido un amplio espectro de poder a favor del titular de la rama ejecutiva, ya que le posibilita el uso de las fuerzas armadas para mantener la seguridad interna del país, circunstancia que veremos a continuación.

\section{ANÁLISIS DE LA LEY DE SEGURIDAD INTERIOR}

El pasado 21 de diciembre del año 2017, fue publicada en el Diario Oficial de la Federación, tras grandes discusiones la nueva Ley de Seguridad Interior, la cual pese a haber sido tachada de inconstitucional por diversos actores de la vida política en México al momento de su publicación, al menos en los albores del año que corre, no había sido objeto de impugnación, ya que por el dicho del ministro presidente, Luis María Aguilar Morales, la Suprema Corte de Justicia de la Nación no había recibido ninguna acción de inconstitucionalidad (Proceso 2018), sin embargo, el 9 de enero de 2018, la Suprema Corte de Justicia de la Nación admitió a trámite la primera controversia constitucional presentada por el municipio de Cholula, Puebla, para impugnarla, la cual quedó registrada bajo el expediente $4 / 2018$, en donde se resolvería si la norma impugnada se apegaba a la Constitución en materia de derechos humanos y de división de poderes. A esta impugnación le siguieron otras, cuyos conceptos acusaron a la ley en comento de falta de transparencia, de

5. Con fecha 15 de noviembre de 2018, el Pleno de la Suprema Corte de Justicia de la Nación (SCJN) invalidó la Ley de Seguridad Interior publicada en el Diario Oficial de la Federación el 21 de diciembre de 2017. 
invasión competencial, de amenazas a la libertad de expresión y de uso indiscriminado de términos vagos y excesivamente amplios (Ángel, 2018).

Volviendo a los orígenes de la ley, es preciso señalar que, en el Senado de la República, fue aprobada por 76 votos a favor contra 44 en contra y 3 abstenciones.

(...) tras casi 12 horas de debate con más de 40 participaciones en tribuna, escaso debate y con el voto fragmentado de la bancada del Partido Acción Nacional (PAN), que se partió: una mitad aprobó el proyecto junto con PRI y Verde, mientras que otra se sumó al bloque PT-Morena, PRD e independientes en contra. (Proceso, 2018).

Aprobada por el Senado como Cámara de origen pasó a los diputados, quienes el 30 de noviembre también la aprobaron por 262 votos a favor, 25 en contra y cero abstenciones.

Como se puede observar no hubo una uniformidad en la votación respecto de esta ley, especialmente en el Senado, particularmente por los poderes que, disfrazados de mecanismo de protección para la sociedad civil, son otorgados al titular de Ejecutivo como se verá más adelante.

La realidad es que esta nueva legislación fue criticada ampliamente no solo por instancias nacionales como la Comisión Nacional de los Derechos Humanos y el Instituto Nacional de Transparencia, acceso a la Información y Protección de datos personales, sino también por la Comisión Interamericana de los Derechos Humanos y desde luego la Organización de las Naciones Unidas.

El proyecto de Ley de Seguridad Interior clasifica información y es contrario a los principios de máxima transparencia en México, por lo que el Instituto Nacional de Transparencia, Acceso a la Información y Protección de Datos Personales (INAI) la criticó este jueves.

El INAI considera que el artículo 9 del dictamen "trasgrede los principios de máxima publicidad, de temporalidad en la reserva y de progresividad, los cuales deben imperar para el ejercicio del derecho humano de acceso a la información", detalló el órgano en un comunicado. (Expansión, 2017).
Como era de esperarse, la Suprema Corte de Justicia de la Nación resolvió invalidar por completo la ley, debido a que su contenido transgredía al texto constitucional.

El Pleno de la Suprema Corte de Justicia de la Nación (SCJN) invalidó la totalidad de la Ley de Seguridad Interior publicada en el Diario Oficial de la Federación el 21 de diciembre de 2017. Por decisión de la mayoría de sus integrantes, el Tribunal Constitucional de nuestro país determinó, en esencia, que dicha ley resultaba inconstitucional al contener disposiciones que pretendían normalizar la utilización de las Fuerzas Armadas en temas de seguridad pública, lo que es contrario al orden constitucional y convencional. Asimismo, una parte de sus miembros se pronunció por la incompetencia del Congreso de la Unión para legislar en la materia de seguridad interior. Con esta resolución la Suprema Corte dio por terminada la revisión de la acción de inconstitucionalidad $6 / 2018$ y sus acumuladas 8/2018, 9/2018, 10/2018 y 11/2018, promovidas por diputados federales, senadores, el Instituto Nacional de Transparencia, Acceso a la Información y Protección de Datos Personales, la Comisión Nacional de los Derechos Humanos y el Partido Político Movimiento Ciudadano, en contra de la referida Ley de Seguridad Interior. (SCJN, 2018).

Ahora bien, más allá de las críticas a esta ley, el elemento central de este breve trabajo versa sobre el empoderamiento que pretendía el Poder Ejecutivo, el cual, desde la época de la presidencia de Ernesto Zedillo había experimentado -como ya se dijo- una clara disminución de su poder, sobre todo después de que dejase de ejercer aquellas facultades que eran conocidas como metaconstitucionales (Carpizo, 2006: 190-199).

Comenzando el análisis de la Ley de Seguridad Interior, nos enfocaremos en su artículo $1 \stackrel{0}{\circ}$, el cual establecía que la materia de la misma es justamente la seguridad nacional, la cual por disposición de la fracción VI del artículo 89 Constitucional resulta ser una competencia exclusiva del presidente de la república, circunstancia con la que no existe objeción alguna.

VI. Preservar la seguridad nacional, en los términos de la ley respectiva, y disponer de la totalidad de la Fuerza Armada permanente o 
sea del Ejército, de la Armada y de la Fuerza Aérea para la seguridad interior y defensa exterior de la Federación (Constitución Política de los Estados Unidos Mexicanos, 2018).

Para comprender lo anterior, debemos precisar que por seguridad nacional se entiende "a todos aquellos programas, medidas e instrumentos que cierto Estado adopta para defender a sus órganos supremos de un eventual derrocamiento violento por un movimiento subversivo interno o una agresión externa." (IIJ-UNAM, 2004: 383).

Un nuevo concepto de seguridad nacional supondría formular nuevos fundamentos para que sea socialmente aceptado, políticamente correcto y culturalmente unificador. Es decir, conseguir que la idea deje de asociarse de manera automática a una concepción represiva, para que sea susceptible de convertirse en un parteaguas que defina los intereses nacionales con independencia de la ideología política profesada. Finalmente, lo más útil para todos sería que la idea de seguridad nacional pudiese emparentarse con la garantía de conseguir los objetivos plasmados en el proyecto nacional, el elemento constitutivo de toda comunidad nacional. (Curzio, 2008: 81).

Derivado de lo antes expresado, también conviene definir qué debemos entender por seguridad interior, pues es ese término uno de los elementos centrales de nuestros comentarios, el cual queda representado en el artículo $2^{\circ}$ de la Ley de Seguridad Interior.

La Seguridad Interior es la condición que proporciona el Estado mexicano que permite salvaguardar la permanencia y continuidad de sus órdenes de gobierno e instituciones, así como el desarrollo nacional mediante el mantenimiento del orden constitucional, el Estado de Derecho y la gobernabilidad democrática en todo el territorio nacional. Comprende el conjunto de órganos, procedimientos y acciones destinados para dichos fines, respetando los derechos humanos en todo el territorio nacional, así como para prestar auxilio y protección a las entidades federativas y los municipios, frente a riesgos y amenazas que comprometan o afecten la seguridad nacional en los términos de la presente Ley (LSI, 2018).
Como puede observarse, la seguridad interior nos habla de la institucionalidad (...salvaguardar la permanencia y continuidad de sus órdenes de gobierno e instituciones, así como el desarrollo nacional mediante el mantenimiento del orden constitucional, el Estado de Derecho y la gobernabilidad democrática en todo el territorio nacional.), y de cómo ciertos riesgos y amenazas vinculadas con lo anterior pueden comprometer la seguridad nacional, es decir, el derrocamiento violento de los órganos supremos de gobierno por un movimiento subversivo interno o una agresión externa.

Ahora bien, como puede apreciar el lector, el tema de la seguridad interior planteado como lo hacía la ley en comento, naturalmente corresponde a lo que comúnmente conocemos como seguridad pública, ya que posibilita el uso de las fuerzas armadas en temas focalizados como el narcotráfico, la delincuencia organizada, etc., temas que si bien pudieran escalar y llegar a poner en jaque al gobierno constitucional, en primera instancia se observan como un asunto de seguridad pública, la cual por disposición constitucional depende de cuerpos de policía ubicados en los ámbitos municipal, estatal y federal, como primera fuerza de respuesta ante problemas del más diverso índole.

La seguridad pública, que es para cuidar la vida y la propiedad de los mexicanos, fue convertida por Carlos Salinas de Gortari en Seguridad Nacional. De entonces a la fecha, y siguiendo puntualmente los deseos de Washington (desde Reagan en 1986), se ha involucrado a las fuerzas castrenses en el combate al narcotráfico y la delincuencia organizada. A cambio, y esto no fue invento de Calderón, se ha aumentado el presupuesto de las fuerzas armadas permanentes, además de adquirir nuevo armamento (Rodríguez, 2011).

De todos es conocido que estas fuerzas policiacas encargadas del orden público han sido infiltradas por el crimen organizado, circunstancia que nos ha llevado a observar un alto nivel de corrupción y por tanto de ineficacia en sus quehaceres cotidianos, hecho que ha provocado que la población ya no confíe en sus instituciones. Ante esta circunstancia, en el sexenio del presidente Calderón fuimos testigos de lo que el propio presidente denominó como la guerra contra el narco, hecho que llevó 
al ejército, armada y fuerza aérea a combatir delitos, vigilar calles, etc., es decir, fue una sustitución de las fuerzas policiales de naturaleza civil por el ejército, sin que se tuviera legalmente esa competencia, de lo cual originó múltiples violaciones a los derechos humanos, derivadas principalmente de la falta de formación profesional por parte de las fuerzas armadas a efecto de atender un tema propio de otras instancias de gobierno, es decir, como muchos lo señalaron, se militarizó la seguridad pública.

A partir de los ochenta, pero sobre todo después del levantamiento armado del Ejército Zapatista de Liberación Nacional (EZLN), el 1oㅡ de enero de 1994, las Fuerzas Armadas han ido tomando un papel cada vez más protagónico en diversos ámbitos de la vida social y política de México (Sandoval, 2000).

José Antonio González Fernández señala que el dilema de la seguridad pública es realizar su función para lograr el mantenimiento de la paz y el orden, sin afectar los derechos y las libertades de los individuos. Las instituciones encargadas de la seguridad pública deben lograr un equilibrio entre la coerción y el respeto de los valores éticos tutelados por el derecho. Así, la protección de los valores fundamentales del hombre legitimará el ejercicio de la fuerza. (Como se cita en Peñaloza y Garza, 2002).

Algo que debemos preguntarnos es ¿a quién corresponde naturalmente la seguridad pública?, y la respuesta nos la brinda el artículo 21 Constitucional, que nos refiere lo siguiente:

(...) La seguridad pública es una función a cargo de la Federación, las entidades federativas y los Municipios, que comprende la prevención de los delitos; la investigación y persecución para hacerla efectiva, así como la sanción de las infracciones administrativas, en los términos de la ley, en las respectivas competencias que esta Constitución señala. La actuación de las instituciones de seguridad pública se regirá por los principios de legalidad, objetividad, eficiencia, profesionalismo, honradez y respeto a los derechos humanos reconocidos en esta Constitución.

Las instituciones de seguridad pública serán de carácter civil, disciplinado y profesional. El Ministerio Público y las instituciones policiales de los tres órdenes de gobierno deberán coordinarse entre sí para cumplir los objetivos de la seguridad pública y conformarán el Sistema Nacional de Seguridad Pública (...) (Constitución Política de los Estados Unidos Mexicanos, 2018).

El texto del artículo precedente lo señala puntualmente: la seguridad pública debe recaer en instituciones de carácter civil a cargo de la Federación, las entidades federativas y los municipios, de manera que la intervención de las fuerzas armadas contraviene tal dispositivo legal. Desde luego hay que entender que al dispersar el control sobre las instituciones de seguridad pública, son muchos los mandos que de ahí surgen, pues aparecen en la escena los presidentes municipales, sus secretarios o directores de seguridad pública, los gobernadores y sus secretarios del ramo en comento y en el ámbito federal el presidente y el secretario de Gobernación, al ser titular de la Comisión Nacional de Seguridad y por tanto de la policía federal; como se observa, el titular del Poder Ejecutivo Federal solamente incide respecto de la instancia de seguridad federal, excluyéndolo del resto, lo cual implica falta de control y de poder.

Bajo esta circunstancia, la participación de las fuerzas armadas en labores de seguridad pública resulta inconstitucional, tal y como lo resolvió recién nuestro máximo tribunal.

Asimismo, el Centro de Investigación y Seguridad Nacional (CISEN), ha mencionado que seguridad nacional y seguridad pública no son sinónimos, pero al final del camino son ideas complementarias, circunstancia que debe considerarse para el análisis.

De acuerdo con la Constitución, la Seguridad Pública es una función concurrente a cargo de los tres niveles de gobierno. Comprende la prevención, investigación y persecución para hacerla efectiva, así como la sanción de las infracciones administrativas.

La Seguridad Pública puede convertirse en asunto de Seguridad Nacional en el grado en que la manifestación del fenómeno criminal represente un riesgo para la integridad, estabilidad y permanencia del Estado, para el orden constitucional, las instituciones democráticas fundadas en el desarrollo social, económico y político, y en el grado en que constituyan un obstáculo para que las autoridades actúen contra la delincuencia organizada (CISEN, 2018). 
En relación a lo anterior, cuando el CISEN habla de que la seguridad pública puede convertirse en un asunto de seguridad nacional, se requiere de un fenómeno que represente un riesgo, y justamente la fracción III del artículo 4 de la Ley de Seguridad Interior menciona que hay riesgo cuando una situación potencialmente puede convertirse en una amenaza, y aquí surge la incógnita de quien hará esta interpretación, derivándola hacia el propio presidente de la República por disposición del artículo $5^{\circ}$, lo cual evidentemente lo empodera, dándole la oportunidad de disponer de las fuerzas armadas de manera bastante libre para efectos de atender asuntos de seguridad pública, y con ello tener presencia y dominio en todo el territorio nacional, desplazando a las autoridades civiles locales.

Ahora nos conviene referirnos al artículo $9^{\circ}$ de la Ley de Seguridad Interior, porque también incide en ese proceso de empoderamiento del titular del Poder Ejecutivo. Este artículo señala que "La información que se genere con motivo de la aplicación de la presente ley, será considerada de Seguridad Nacional, en los términos de las disposiciones jurídicas aplicables."

El texto del artículo precedente nos refiere a la posibilidad de guardar información pública bajo el manto protector que se otorga a la información de seguridad nacional, la cual, por disposición de las Leyes General y Federal de Transparencia y Acceso a la Información Pública, queda como información reservada y por tanto restringida.

Artículo 110. Conforme a lo dispuesto por el artículo 113 de la Ley General, como información reservada podrá clasificarse aquella cuya publicación: I. Comprometa la seguridad nacional, la seguridad pública o la defensa nacional y cuente con un propósito genuino y un efecto demostrable; (LGTAIP, 2018).

Artículo 113. Como información reservada podrá clasificarse aquella cuya publicación: I. Comprometa la seguridad nacional, la seguridad pública o la defensa nacional y cuente con un propósito genuino y un efecto demostrable; (LGTAIP, 2018).

Resulta curioso el texto del artículo $8^{\circ} \mathrm{de}$ la Ley Federal de Transparencia y Acceso a la Información Pública, en el sentido de señalar que aquella información vinculada con violaciones graves a derechos humanos no podrá ser considerada como reservada y entonces nos preguntamos ¿qué sucederá con las acciones derivadas de la aplicación de la Ley de Seguridad Interior que violenten derechos humanos?, ¿se considerarán como un asunto de seguridad nacional y por ello información reservada o no?, la realidad es que el asunto pareciera derivar en un bonito enredo legal que desde luego lastima nuestro estado de derecho y muestra una cara desaseada de nuestro sistema jurídico.

Artículo 8. No podrá clasificarse como reservada aquella información que esté relacionada con violaciones graves a derechos humanos o delitos de lesa humanidad, de conformidad con el derecho nacional o los tratados internacionales de los que el Estado mexicano sea parte. (LFTAIP, 2018).

Hay que señalar que esta circunstancia resulta claramente violatoria de derechos humanos, lo cual también se traduce en un empoderamiento en favor del presidente, pues le ampliaría las posibilidades de actuación sin preocuparse de la responsabilidad que implica sacar a las fuerzas armadas a la calle a cumplir funciones de seguridad pública -aspecto para el que no se encuentran debidamente capacitadas-, amparados en preceptos que nuestra Suprema Corte de Justicia señaló como inconstitucionales.

Dicho esto, pasemos a analizar el contenido del artículo 11 de la (LSI) Ley de Seguridad Interior, el cual, grosso modo establecía que el presidente de la República tendría la facultad de ordenar por sí mismo la intervención de las fuerzas federales para la realización e implementación de Acciones de Seguridad Interior, es decir, se posibilitaba la intervención del Ejército armada y fuerza aérea para realizar e implementar acciones de seguridad interior, lo que implica en pocas palabras, que su intervención sería en materia de seguridad pública, circunstancia que solamente requería de una declaratoria de protección por amenazas a la seguridad interior del país.

Amenazas a la Seguridad Interior: Las que afecten los principios establecidos en el artículo 3 y las contenidas en el artículo 5 de la Ley de Seguridad Nacional que tienen su origen en territorio nacional; las emergencias o desastres naturales en un área o región geográfica del país; las epidemias y demás contingencias que afecten la salubridad 
general; o las que afecten los deberes de colaboración de las entidades federativas y municipios en materia de seguridad nacional; (LSI, 2018).

Artículo 3.- Para efectos de esta ley, por Seguridad Nacional se entienden las acciones destinadas de manera inmediata y directa a mantener la integridad, estabilidad $y$ permanencia del Estado Mexicano, que conlleven a: I. La protección de la nación mexicana frente a las amenazas y riesgos que enfrente nuestro país;

II. La preservación de la soberanía e independencia nacionales y la defensa del territorio;

III. El mantenimiento del orden constitucional $\mathrm{y}$ el fortalecimiento de las instituciones democráticas de gobierno;

IV. El mantenimiento de la unidad de las partes integrantes de la Federación señaladas en el artículo 43 de la Constitución Política de los Estados Unidos Mexicanos;

V. La defensa legítima del Estado mexicano respecto de otros Estados o sujetos de derecho internacional, y

VI. La preservación de la democracia, fundada en el desarrollo económico social y político del país y sus habitantes. (LSN 2018).

Artículo 5.- Para los efectos de la presente ley, son amenazas a la Seguridad Nacional:

I. Actos tendentes a consumar espionaje, sabotaje, terrorismo, rebelión, traición a la patria, genocidio, en contra de los Estados Unidos Mexicanos dentro del territorio nacional;

II. Actos de interferencia extranjera en los asuntos nacionales que puedan implicar una afectación al Estado mexicano;

III. Actos que impidan a las autoridades actuar contra la delincuencia organizada;

IV. Actos tendentes a quebrantar la unidad de las partes integrantes de la Federación, señaladas en el artículo 43 de la Constitución Política de los Estados Unidos Mexicanos;

V. Actos tendentes a obstaculizar o bloquear operaciones militares o navales contra la delincuencia organizada;

VI. Actos en contra de la seguridad de la aviación;

VII. Actos que atenten en contra del personal diplomático;
VIII. Todo acto tendente a consumar el tráfico ilegal de materiales nucleares, de armas químicas, biológicas y convencionales de destrucción masiva;

IX. Actos ilícitos en contra de la navegación marítima;

$\mathrm{X}$. Todo acto de financiamiento de acciones y organizaciones terroristas;

XI. Actos tendentes a obstaculizar o bloquear actividades de inteligencia 0 contrainteligencia, $\mathrm{y}$

XII. Actos tendentes a destruir o inhabilitar la infraestructura de carácter estratégico o indispensable para la provisión de bienes o servicios públicos.

Si bien es cierto que el artículo 12 de la ley en comento señalaba que el presidente de la República, previa consideración del Consejo de Seguridad Nacional, determinaría la procedencia de la intervención de la Federación, no debemos perder de vista cual era la relación que guardaba dicho Consejo con el titular del Ejecutivo. En este sentido debemos afirmar que el Consejo era una instancia deliberativa encabezada por el propio titular del Ejecutivo Federal, a efecto de establecer y articular las acciones y políticas en materia de Seguridad Nacional, hecho que fácticamente lo deja bajo su comando y dirección.

Artículo 12.- Para la coordinación de acciones orientadas a preservar la Seguridad Nacional se establece el Consejo de Seguridad Nacional, que estará integrado por:

I. El titular del ejecutivo federal, quien lo presidirá;

II. El secretario de gobernación, quien fungirá como secretario ejecutivo;

III. El secretario de la Defensa Nacional;

IV. El secretario de la Marina;

V. El secretario de Seguridad Pública;

VI. El secretario de Hacienda y Crédito Público;

VII. El secretario de la Función Pública;

VIII. El secretario de Relaciones Exteriores;

IX. El secretario de Comunicaciones y Transportes;

X. El procurador general de la república, y XI. El director general del Centro de Investigación y Seguridad Nacional.

Los integrantes del Consejo no podrán nombrar suplente. En caso de ausencia del 
presidente, el Secretario Ejecutivo presidirá la reunión. El Consejo contará con un Secretario Técnico, que será nombrado por el presidente de la República, dependerá directamente de él, contará con un equipo técnico especializado y un presupuesto asignado en el Presupuesto de Egresos de la Federación. Este no será integrante del Consejo. (LSI, 2018).

Otro elemento determinante en el empoderamiento del titular de la rama ejecutiva tiene que ver con las declaratorias de protección a la seguridad interior, la cual en primera instancia se mostraban benévolas en términos de que la intervención de la federación debía estar sujeta a una vigencia específica, lo cual parecería brindar certeza jurídica, sin embargo, el propio artículo 15 de la ley en crítica puntualizaba que las condiciones y la vigencia de esas declaratorias podían modificarse o prorrogarse por acuerdo del Presidente de la República, dejándole con ello un efecto discrecional de dimensiones potencialmente peligrosas.

En México, mucha gente está muy acostumbrada a creer que todas las cosas pueden darse por decreto y que de esta forma todo puede suceder, dejando de lado consideraciones como la cultura y la idiosincrasia de la gente.

Dicho esto, el artículo 17 de la multicitada ley señalaba que: a partir de la expedición de la Declaratoria de Protección a la Seguridad Interior, las acciones que realizaran las autoridades federales para su atención y cumplimiento, se considerarían como Acciones de Seguridad Interior. (LSI, 2018).

Para efectos prácticos, la sola Declaratoria de Protección a la Seguridad Interior, convertía de un plumazo a todos los actos desplegados como acciones de seguridad interior, es decir, justificaba los actos realizados por las fuerzas armadas equiparándolos incluso a actos de seguridad pública, aunque el legislador señalaba en el propio artículo 18 que esto no sucedería. Resulta evidente que la sustitución que hicieran las fuerzas armadas respecto de las autoridades civiles era para asumir sus roles, que particularmente tenían que ver con la seguridad pública.

Es claro que la situación que reina en nuestro país en materia de seguridad pública es bastante crítica; y pareciera que las autoridades locales están completamente rebasadas; que los particulares ante tal situación están tomando la justicia en sus manos, circunstancia que hemos estado viendo con los cada vez más frecuentes linchamientos de presuntos delincuentes. Esta situación, aunque crítica no debe llevarnos a tomar medidas desesperadas que pueden generar mayores problemas de los que ya tenemos.

Buscar el empoderamiento de la figura presidencial a costa de trastocar el orden constitucional y sobre todo pisotear derechos humanos, simplemente no puede ser. Hoy debemos comprender que la gobernabilidad democrática en un país debe construirse todos los días a partir de acuerdos entre las fuerzas políticas, sobre todo en países como el nuestro donde ya no existe un predominio del Ejecutivo sobre las demás funciones. Hoy más que nunca es tiempo de considerar las coaliciones de gobierno para alcanzar esos acuerdos y llevar a México a un mejor estadio de vida.

\section{CONCLUSIONES}

Resulta evidente que el ejercicio del poder requiere de herramientas adecuadas para lograr su cometido. En el caso mexicano - como en muchos otros países- el uso de las fuerzas armadas ha sido un elemento central en el ejercicio del poder.

La delincuencia y la corrupción en las instituciones encargadas de la seguridad pública se han desbordado y han contribuido a reducir el margen de maniobra de los gobiernos en México, razón por la que han echado mano de las fuerzas armadas para mantener la gobernabilidad democrática en el país, circunstancia que ha derivado en sendas violaciones a los derechos humanos.

La emisión de la Ley de Seguridad Interior respondió a esa búsqueda del empoderamiento que requería el gobierno de Enrique Peña Nieto, sin embargo, el contenido de la ley resultó violatorio del texto constitucional, particularmente por orientar el uso de las fuerzas armadas para funciones que evidentemente eran de seguridad pública, cuyo ejercicio corresponde exclusivamente a autoridades civiles.

Si bien es cierto que la ley ya fue declarada como inconstitucional, su creación y orientación nos dieron el pretexto necesario para mostrar 
cómo es que el Poder Ejecutivo pretendía seguir utilizando a las fuerzas armadas, circunstancia que parece que se repetirá con el actual gobierno, ya que se pretende crear una guardia nacional con cierto contenido de naturaleza militar, para atender asuntos de seguridad pública.

Es tiempo de pensar en mejores estrategias de velar por la seguridad pública, la cual comienza ahí en las comunidades, donde debiera haber fuerzas de seguridad pública confiables, bien adiestradas y con remuneraciones dignas, que impidan -en la medida de lo posible- la infiltración del crimen organizado entre sus filas.
Hoy debemos reconocer que existen muchos servidores públicos y particularmente elementos de seguridad pública honrados y verdaderamente comprometidos con su difícil tarea, a quienes hay que apoyar para que sociedad y gobierno logren salvaguardar un estilo de vida decoroso, donde las personas se sientan tranquilas y dispuestas a trabajar para lograr un mejor futuro para todos, un futuro que todos deseamos y al que podemos aspirar si es que unimos fuerzas, teniendo como bandera el pleno respeto por los derechos humanos.

\section{BIBLIOGRAFÍA}

- Ángel, A. (2018). Las 5 razones por las que la Ley de Seguridad Interior es inconstitucional, según amparos. Recuperado de: https:// www.animalpolitico.com/2018/05/5razones-ley-seguridad-interior-esinconstitucional/

- Carpizo, J. (2006). El presidencialismo mexicano. México: Siglo XXI Editores.

- CISEN. (2018). Seguridad nacional y seguridad pública, Recuperado de http:// www.cisen.gob.mx/snPrincipiosTema1. html

- CONAgo. (2018). Sobre la Conago. Recuperado de https://www.conago.org. $\mathrm{mx} /$ acercade/sobre-la-conago

- Congreso Constituyente. Constitución Política de los Estados Unidos Mexicanos (CPEUM). Diario Oficial de la Federación, 5 de febrero de 1917. Recuperado de http://www.diputados.gob. $\mathrm{mx} /$ LeyesBiblio/pdf/1_150917.pdf

- Curzio, L. (2008). La seguridad nacional en México. Recuperado de http://www.cisan. unam.mx/pdf/lc02_04.pdf

- Expansión. (2017). El INAI advierte que la Ley de Seguridad Interior es contraria a la transparencia. Recuperado de: http:// expansion.mx/nacional/2017/12/07/ el-inai-advierte-que-ley-de-seguridadinterior-es-contraria-a-la-transparencia

- Hobbes, T. (2006). El Leviatán. México: Fondo de Cultura Económica.

- Instituto de Investigaciones Jurídicas de la UNAM, (2004). Enciclopedia Jurídica Mexicana. México: Porrúa-UNAM.

- Jellinek, G. (2004). Teoría general del Estado. México: Fondo de Cultura Económica.

- Krauze, E. (2007). La presidencia imperial. México: Fabula Tusquets Editores.

- Ley de Seguridad Interior. (LSI). (2017). Recuperado de http://www.diputados.gob. $\mathrm{mx} /$ LeyesBiblio/pdf/LSInt_211217.pdf

- Ley General de Transparencia y Acceso a La Información Pública (LGTAIP). (2015). Recuperado de http://www.diputados. gob.mx/LeyesBiblio/pdf/LGTAIP.pdf

- Ley Federal de transparencia y acceso a la información pública. (LFTAIP). Ley de Seguridad Interior. (LSI). Recuperado de http://www.diputados.gob.mx/ LeyesBiblio/pdf/LFTAIP_270117.pdf

- Maquiavelo, Nicolás. (1993). El Príncipe. México: Porrúa.

- Medin, Tzivi. (2003). Ideología y praxis política de Lázaro Cárdenas. México: Siglo XXI Editores. 
- NATIONAL GEOGRAPHIC, (2014). La guardia pretoriana, la escolta de los emperadores. Recuperadodehttp://www.nationalgeographic.com.es/historia/grandes-reportajes/ la-guardia-pretoriana_8142/5

- Peñaloza, P. (2002). Los desafíos de la seguridad pública en México. México: Instituto de Investigaciones Jurídicas de la UNAM.

- Revista Proceso. (2018). Nadie ha impugnado la Ley de Seguridad Interior: SCJN. Recuperado de http://www.proceso.com. $\mathrm{mx} / 517012 /$ nadie-ha-impugnado-la-leyde-seguridad-interior-scjn

- Rodríguez, O. (2011) De seguridad pública a seguridad nacional. En La Jornada. 8 de septiembre de 2011. La Jornada. Recuperado de http://www.jornada.unam. $\mathrm{mx} / 2011 / 09 / 08 /$ opinion/022a1pol

- Sandoval, J. (2000). Militarización, seguridad nacional y seguridad pública en México. Espiral, 6 (18), 183-222. Recuperado de http://www.redalyc.org/articulo. oa?id=13861806
- Senado de la República. (2006). Conformación del Congreso de la Unión. Boletín informativo, Año I, No. 40. Recuperado de http://www.senado.gob. $\mathrm{mx} /$ library/archivo_historico/contenido/ boletines/boletin_40.pdf

- Serrano, F. (2006). Facultades metaconstitucionales del poder ejecutivo en México. Buenos Aires: Universidad de Palermo. Recuperado de https://www.palermo.edu/ derecho/publicaciones/sela2006_pdf/ Fernando_Serrano.pdf

- Suprema Corte de Justicia de la Nación (SCJN). (2018). La Suprema Corte de Justicia de la Nación invalidó la ley de seguridad interior en su totalidad. Recuperado de http:// www.internet2.scjn.gob.mx/red2/comunicados/noticia. asp?id=5794

- Valadés, D. (2016). Los gobiernos de coalición en América Latina. México: Colegio Nacional.

- Weber, M. (2002). Economía y Sociedad. Madrid: Fondo de Cultura Económica. 